\title{
Ultrafast Carrier Trapping of a Metal-doped Titanium Dioxide Semiconductor Revealed by Femtosecond Transient Absorption Spectroscopy
}

Jingya Sun, ${ }^{1}$ Yang Yang, ${ }^{2}$ Jafar I. Khan,,${ }^{1}$ Erkki Alarousu, ${ }^{1}$ Zaibing Guo, ${ }^{2}$ Xixiang Zhang, ${ }^{2}$ Qiang Zhang, ${ }^{2}$ and Omar F. Mohammed ${ }^{* 1}$

${ }^{1}$ Solar and Photovoltaic Engineering Research Center, Division of Physical Sciences and Engineering, King Abdullah University of Science and Technology, Thuwal 23955-6900, Saudi Arabia

${ }^{2}$ Advanced Nanofabrication and Imaging Core Lab, King Abdullah University of Science and Technology, Thuwal 23955-6900, Saudi Arabia

Address correspondence to omar.abdelsaboor@kaust.edu.sa (O.F.M.) 


\begin{abstract}
We explored for the first time the ultrafast carrier trapping of a metal-doped titanium dioxide $\left(\mathrm{TiO}_{2}\right)$ semiconductor using broadband transient absorption (TA) spectroscopy with 120 femtosecond (fs) temporal resolution. The titanium dioxide was successfully doped layer-by-layer with two metals ions namely Tungsten (W) and Cobalt (Co). The time-resolved data demonstrate clearly that the carrier trapping time decreases progressively as the doping concentration increases. A global fitting procedure for the carrier trapping suggests the appearance of two time components: a fast one that is directly associated with carrier trapping to the defect state in the vicinity of the conduction band and a slow component that is attributed to carrier trapping to the deep level state from the conduction band. With a relatively long doping deposition time on order of 30 seconds, a carrier lifetime of about 1 picosecond is obtained. To confirm that the measured ultrafast carrier dynamics are associated with electron trapping by metal doping, we explored the carrier dynamics of the un-doped $\mathrm{TiO}_{2}$. The findings reported here may be useful to the implementation of high-speed optoelectronic applications and fast switching devices.
\end{abstract}

Keywords: Ultrafast carrier trapping, titanium dioxide, transient absorption spectroscopy, metal-doped, deep level state. 


\section{Introduction}

Semiconductor $\mathrm{TiO}_{2}$ is a widely studied material ${ }^{1-7}$ due to the chemical stability, nontoxic nature, inexpensive fabrication and abundance in nature. ${ }^{8}$ This highly versatile material has found many applications in a variety of research areas of significance, including electronics, ${ }^{9}$ photovoltaics, ${ }^{10}$ photocatalysis ${ }^{3}$ and photoelectrochemical conversion. ${ }^{11-13}$ A prominent example is the use of the photocatalytic properties derived from $\mathrm{TiO}_{2}{ }^{1,14}$ in the formation of photogenerated charge carriers (electron-hole pairs), which occur with the absorption of ultraviolet (UV) light. In addition, $\mathrm{TiO}_{2}$ is classified as a unique photocatalyst under light doping in both the visible and UV regions. ${ }^{4,9,15}$ It is in fact true that the long carrier lifetimes of un-doped $\mathrm{TiO}_{2}$ prevent its use in other potential applications, such as high-frequency switching devices and photo-detectors, which mainly rely on very fast carrier recombination as a recovery process to the initial state. In this regard, doping of $\mathrm{TiO}_{2}$ using metal agents is quite beneficial as is evidenced in new localized electronic energy levels, defect levels and a deep-level trap state, induced in the band gap. ${ }^{6,16}$ Essentially, an electron is successfully excited from the valence band (VB) to the conduction band followed by trapping to the generated defect states. Accordingly, in this regime, it is well documented that deep-level states within the band gap can significantly reduce the carrier lifetime. Thus, efforts have been devoted to making these materials suitable for unique applications, including repetitive ultrafast electrical transients and high-speed electronics. ${ }^{17,18}$

Gathering detailed information on intrinsic carrier recombination dynamics due to the metallic dopants in $\mathrm{TiO}_{2}$ is important. Quantitative data on these carrier dynamics can be directly obtained through ultrafast pump-probe spectroscopy. As a consequence of the action of the pump pulse, electrons are successfully promoted to the conduction band (CB) and subsequently the decay process from the latter band to various defect levels can be directly probed in real time. To achieve this, transient absorption (TA) spectroscopy is a highly sensitive, broadband and powerful tool that allows the exploration of the ultrafast carrier dynamics in semiconductor materials and complex molecular systems. ${ }^{16,19-23}$ For instance, ultrafast carrier dynamics have been thoroughly investigated in numerous of semiconductor materials by implementation of this technique, including $\mathrm{SrTiO}_{3}{ }^{6,24} \mathrm{ZnO}^{25} \mathrm{ZrO}_{2}{ }^{26}$ In this letter, we report results from unambiguous, time- 
resolved experiments on carrier trapping in metal-doped $\mathrm{TiO}_{2}$ as a function of the deposition time of two metals, Tungsten (W) and Cobalt (Co). We clearly show that the carrier recombination time decreases dramatically as the metal deposition time increases. Two time constants for the carrier trapping are observed, a fast component with a characteristic time constant of a few picoseconds associated with the trapped carriers near the conduction band and a slow component of a hundred picoseconds attributed to the trapped carriers in the deep-level state.

\section{Experimental Section}

In this section, we outline the experimental scheme, which includes the synthesis method of the materials and the ultrafast femtosecond transient absorption spectroscopy technique.

$\mathrm{TiO}_{2}-\mathrm{M}-\mathrm{TiO}_{2}(\mathrm{M}=\mathrm{W}$ and $\mathrm{Co})$ Multilayer Film Synthesis: The procedure for the sample preparation was previously reported in detail. ${ }^{27}$ We provide a brief description with the particular samples used in this work. $\mathrm{TiO}_{2}-\mathrm{M}-\mathrm{TiO}_{2}(\mathrm{M}=\mathrm{W}$ and $\mathrm{Co})$ multilayer films were deposited on glass substrates using radio frequency (RF) reactive magnetron sputtering. For each sample, four layers of $\mathrm{TiO}_{2}$ and three layers of the selected metal were deposited. Alternately one layer of $\mathrm{TiO}_{2}$ and one layer of the metal were deposited as this procedure was repeated three times. After the $\mathrm{TiO}_{2} /$ metal layers were deposited, an additional layer of $\mathrm{TiO}_{2}$ was added as a cover. The total thickness of the $\mathrm{TiO}_{2}$ layers was about $80 \mathrm{~nm}$. The deposition rate of the $W$ and Co layers was 10 and $5.3 \mathrm{~nm} / \mathrm{min}$, respectively, and two different deposition times of 10 and $30 \mathrm{~s}$ were selected. After deposition, all $\mathrm{TiO}_{2}-\mathrm{M}-\mathrm{TiO}_{2}$ films were annealed at $500{ }^{\circ} \mathrm{C}$ in air for 2 hours.

Transmission electron microscope (TEM) cross-section specimens were prepared using the focused ion beam (FIB) technique on a FEI Helios 400S to identify the structure of the $\mathrm{TiO}_{2}$ films and the concentration of the metal dopants. The TEM and scanning transmission electron microscopy (STEM) images were obtained using a FEI Titan 80-300 SuperTwin electron microscope, operated at $300 \mathrm{kV}$. To analyze the state of the dopant agents and clarify the distribution within the multilayer thin films, electron 
energy-loss spectroscopy (EELS) was performed on a Gatan Imaging Filter (GIF) Tridiem.

Femtosecond Transient Absorption Spectroscopy: Ultrafast time-resolved transient absorption spectroscopy ${ }^{28,29}$ was used to study the carrier trapping. An Ultrafast Systems Helios UV-NIR (Ultraviolet-Near Infrared) system was used to explore the semiconductor samples in this study by employing the pump-probe technique (See Figure 3). The Helios is equipped with CMOS VIS (Visible) and fast InGaAs NIR spectrometers covering the wavelength range of $350-800 \mathrm{~nm}$ with $1.5 \mathrm{~nm}$ spectral resolution at 9500 spectra/s and a range of $800-1600 \mathrm{~nm}$ with $3.5 \mathrm{~nm}$ spectral resolution at $7900 \mathrm{spectra} / \mathrm{s}$, respectively.

The output pulse from the laser system is split into two parts to generate the pump and probe pulses. A small portion $(\approx 60 \mu \mathrm{J})$ of the Spitfire (Spectra-Physics Pro 35F-XP regenerative femtosecond amplifier) output is routed via a delay line, adjustable pinholes, a focusing lens and a variable neutral density filter to a crystal for white light continuum (WLC) generation and further to the sample via a focusing mirror. Three crystals are available to cover the UV-VIS and NIR spectrum. A computer-controlled delay line is used to vary the time delay between the pump and probe pulses that allows for transient absorption measurements within a 3.3 ns time window. For the UV-Vis white light continuum generation, we used $\mathrm{CaF}_{2}$ crystal and sapphire plate for 340-700 nm and 440-830 nm spectral ranges, respectively. Another part $(1 \mathrm{~mJ})$ of the Spitfire output is used to pump TOPAS-C (Spectra Physics) two-stage parametric amplifier equipped with frequency mixing stages and a non-collinear difference frequency generator that allows for tuning from 237 to $2700 \mathrm{~nm}$. The TOPAS-C output beam is routed via the adjustable pinholes, a variable neutral density filter, a depolarizer, a chopper wheel and a focusing lens to excite the sample. The pump and probe beams are set to overlap spatially and temporally at the surface of the various thin films. The transmitted probe light from the samples is collected and focused on the broadband detector for recording the time-resolved excitation-induced difference spectrum $(\Delta \mathrm{A})$. During the measurements, the various thin films are constantly moved using a two-stage sample holder such that a fresh sample is 
available for each laser shot as well as to prevent a potentially substantial laser-induced heating effect on the films. The experiments were conducted at the room temperature.

\section{Results and Discussion}

The fundamental features of the samples in terms of the classified diffusion of the metal ions and the respective oxides into the host $\mathrm{TiO}_{2}$ layer were explored in detail. The core observation is that the dopant agents are mainly metal ions in the host ionic crystal of $\mathrm{TiO}_{2}$. Here, we fully characterized the prepared Co-doped $\mathrm{TiO}_{2}$ thin films by TEM and EELS; previously, they were investigated by x-ray diffraction (XRD) and Raman spectroscopy techniques. $^{27}$ The TEM image clearly confirms the preserved multilayer structures of the thin films even after the annealing process with four layers of $\mathrm{TiO}_{2}$ and three layers of the respective metals well-defined and clearly distinguishable as presented in Figure 1A. The inset high-resolution TEM image shows that the $\mathrm{TiO}_{2}$ layers are partially crystallized, agreeing well with previous XRD and Raman results. ${ }^{27}$

In addition, we used EELS scans of the cross-section (Figure 1B) of the samples to investigate the actual diffused concentration of the metal ions into the $\mathrm{TiO}_{2}$ layer. The obtained EELS spectra were acquired from the metal layer to the center of the $\mathrm{TiO}_{2}$ layer as indicated in the figure by position P1 (the metal layer), $\mathrm{P} 2$ and $\mathrm{P} 3$ (both in the $\mathrm{TiO}_{2}$ layer). In the $\mathrm{Co} / \mathrm{TiO} 2$ (ions and oxides) films, we found that the amount of $\mathrm{Co}$ ions diffused into the $\mathrm{TiO}_{2}$ layer (P3) was relatively substantial. In addition, the significant relative difference in the elementary ratio of $\mathrm{Co} /(\mathrm{Co}+\mathrm{Ti})$ between $\mathrm{Co} / \mathrm{TiO}_{2}-10 \mathrm{~s}$ and $\mathrm{Co} / \mathrm{TiO}_{2}-30 \mathrm{~s}$ is mainly apparent in the Co layer at $26.923 \%$ and $66.019 \%$, respectively (Table 1). At positions $\mathrm{P} 2$ and $\mathrm{P} 3$, there is a remarkable decrease in these respective values compared with the case of the initial state (P1) but the actual percentages of diffused Co ions at P3 are $2.299 \%$ and $2.899 \%$, confirming that Co was dispersed into $\mathrm{TiO}_{2}$ layers. This is consistent with the transient absorption data (see below). 
Apparently, the exact concentration of Co and W dopant atoms involved a large inaccuracy but, on the other hand, there was no clear signature to predict the possibility of the appearance of cobalt oxides and tungsten oxides in the actual layer of $\mathrm{Co} / \mathrm{TiO}_{2}-10 \mathrm{~s}$ and $\mathrm{W} / \mathrm{TiO}_{2}-10 \mathrm{~s}$. The reason might be due to the relatively high amount of $\mathrm{Ti}$ effectively suppressing the crystallization of cobalt oxides especially in $\mathrm{Co} / \mathrm{TiO}_{2}-10 \mathrm{~s}$. Direct evidence of the presence of cobalt oxides and tungsten oxides in $\mathrm{Co} / \mathrm{TiO}_{2}-10 \mathrm{~s}$ and $\mathrm{W} / \mathrm{TiO}_{2}-10 \mathrm{~s}$ was not observed in either the XRD and Raman spectroscopy experiments. However, we cannot exclude the possibility that the associated oxides were partially diffused into the layers $\mathrm{Co} / \mathrm{TiO}_{2}-30 \mathrm{~s}$ and $\mathrm{W} / \mathrm{TiO}_{2}-30 \mathrm{~s}$ due to the actual relatively high percentage of Cobalt and Tungsten in the respective metal layers. However, if we assumed that a small fraction of $\mathrm{Co}$ or $\mathrm{W}$ is present as metal oxides, this will not add appreciable uncertainty to the measured ultrafast carrier dynamics because these oxides will have their own band gap rather than creating electron trap states in the band gap of $\mathrm{TiO}_{2}$, which is responsible for the quenching of the excited carrier.

The elementary ratio of $\mathrm{Co} /(\mathrm{Co}+\mathrm{Ti})$ in the $\mathrm{TiO}_{2}$ layer is approximately below $7 \%$ as indicated in Table 1, in good agreement with Griffin and Chambers et al., ${ }^{30,31}$ who claimed that the maximum dopant concentration of $\mathrm{Co}$ ions associated with $\mathrm{TiO}_{2}$ films can reach $10 \%$. Nevertheless, more Co ions are contained in the $\mathrm{TiO}_{2}$ configuration of $\mathrm{Co} / \mathrm{TiO}_{2}-30 \mathrm{~s}$ compared with the case of $\mathrm{Co} / \mathrm{TiO}_{2}-10 \mathrm{~s}$. This observation was confirmed by our ultrafast spectroscopy results (see below).

The surface analysis demonstrated that Co ions and $\mathrm{W}$ ions indeed diffused into the $\mathrm{TiO}_{2}$ layer and served as dopant agents and subsequently caused the modification of the electronic band structure. In addition, the respective oxides and $\mathrm{O}$ ions were incorporated alongside the atoms in the $\mathrm{TiO}_{2}$ layer. It is appropriate to clarify that a small percent of the atoms were dispersed into the $\mathrm{TiO}_{2}$ layer despite the fact the distribution was inhomogeneous as suggested by the TEM and EELS scans. Spatial compositional variations were clearly present and the deviations were pronounced but the atoms and the metal ions were both present in this regime. It is worth pointing out that the inhomogeneity of the metal distribution did not affect the measured dynamics because we 
performed our transient absorption experiment in a transmission mode and the measured signal reflected the average dynamics of the excited area.

The obtained results from the steady-state and ultrafast transient absorption spectroscopy are discussed. It is appropriate to mention that the measurements were ensemble averages. In Figure 2, we present the steady-state absorption spectra of the undoped $\mathrm{TiO}_{2}$ (A) and the doped $\mathrm{TiO}_{2}-\mathrm{Co}-\mathrm{TiO}_{2}(\mathrm{~B})$ and $\mathrm{TiO}_{2}-\mathrm{W}-\mathrm{TiO}_{2}$ (C) films with the wavelength ranging from 300 to $1500 \mathrm{~nm}$. The absorption edges of the $\mathrm{TiO}_{2}-\mathrm{M}-\mathrm{TiO}_{2}$ multi-layer thin films are red-shifted compared with the fundamental absorption edge, which is ascribed to the dopant metals that effectively cause a change in the band gap energy of the $\mathrm{TiO}_{2}$ thin films. In other words, this observation indicates that the band structure of $\mathrm{TiO}_{2}$ is modified significantly by metal doping. This red shift of the $\mathrm{TiO}_{2}$ spectrum can be attributed to doping with ions of low electrical negativity since this mechanism is associated with the ability of an atom to attract the electron density towards itself. $^{32}$ In addition, very often, a shift in the band gap transitions toward longer wavelengths is observed in the doped layers ${ }^{33}$ in good agreement with our observation. It is worth mentioning that the band gap of $\mathrm{TiO} 2$ polycrystalline thin film can be varied from 3.5$3.0 \mathrm{eV}$ with tail down to visible spectrum range. This depends on post-deposition annealing, lattice constants, grain size, morphology, defects including oxygen ones, and annealing temperature. ${ }^{34-38}$

Our experimental setup to conduct highly sensitive transient absorption measurements executed by the pump-probe technique is displayed in Figure 3. The transient absorption spectra obtained by probing with white light in the UV-VIS range after $350 \mathrm{~nm}$ excitation are shown in Figure 4 for the case of un-doped $\mathrm{TiO}_{2}$ and $30 \mathrm{~s}$ deposition time for $\mathrm{W}$ and $\mathrm{Co}$ doped $\mathrm{TiO}_{2}$. The probed data display clear excited states for decay times ranging from - $0.7 \mathrm{ps}$ to $103 \mathrm{ps}$ for the $30 \mathrm{~s}$ deposition time. The pronounced effect indicates that the transient spectra strongly depend on the doping deposition time. Consistency red shift as in the steady-state spectrum is clearly demonstrated throughout the displayed data. Utilizing a global fitting procedure, we report our major findings in terms of the characteristics of the trapped carrier states in Figure 5. Figure 5A shows the carrier recombination of the un-doped and $\mathrm{Co}$ doped $\mathrm{TiO}_{2}$ films As can be clearly seen, the carrier dynamics of the un-doped $\mathrm{TiO}_{2}$ is much slower 
than the doped ones, indicating that the measured ultrafast carrier dynamics are associated with carrier trapping to the defect states created in the $\mathrm{TiO}_{2}$ band gap by metal doping. Each decay curve has a fast component associated with a time constant of about 2-8 ps and a slow component with a time constant of 40-160 ps. More precisely, in the $\mathrm{Co} / \mathrm{TiO}_{2}-10$ s system, two different time components are found with values of $\tau_{1}=4.2 \pm$ $0.40 \mathrm{ps}$ and $\tau_{2}=135 \pm 12.0 \mathrm{ps}$. In the case of $\mathrm{Co} / \mathrm{TiO}_{2}-30 \mathrm{~s}$, the time components are $\tau_{1}=$ $1.8 \pm 0.35 \mathrm{ps}$ and $\tau_{2}=32 \pm 2.7 \mathrm{ps}$. Analogously, the time components for $\mathrm{W} / \mathrm{TiO}_{2}-10 \mathrm{~s}$ are $\tau_{1}=7.5 \pm 0.85 \mathrm{ps}$ and $\tau_{2}=159.3 \pm 15.0 \mathrm{ps}$ and for $\mathrm{W} / \mathrm{TiO}_{2}-30 \mathrm{~s}$ they are $\tau_{1}=3.8 \pm 0.65$ ps and $\tau_{2}=77.9 \pm 7.6$ ps. It should be noted that the carrier trapping is estimated by fitting the kinetic data with a two-exponential decay function: $\Delta A=A_{1} \exp \left(-t / \tau_{1}\right)+$ $A_{2} \exp \left(-t / \tau_{2}\right)$, where $A_{i}$ and $\tau_{i}, i=1$ and 2 are the time-independent coefficients and the time constants determined by the excitation fluence. As can be seen, the carrier trapping of $\mathrm{W} / \mathrm{TiO}_{2}-30 \mathrm{~s}$ is almost a factor of two slower compared with that for $\mathrm{Co} / \mathrm{TiO}_{2}-30$ s. The determined time components are associated with fast and slow times, respectively. The former one is linked to the decay of the electron to the defect state located below the conduction band. Similarly, the second time component is attributed to electrons decaying to the deep-level trapping state allocated between the valence band and the conduction band, near the center of the band gap. These findings associated with the concentration gradient are consistent with the literature ${ }^{39}$ as the generated defect states are shifted (closer to the conduction band edge) as the doping concentration is increased, eventually providing a faster trapping time.

A similar result was observed for other doped semiconductor materials. 6, 16,24-26,40 In these cases, the slow component is also attributed to the carrier trapping in the deeplevel energy states, which can attract electrons from the conduction band or holes from the valence band. Essentially, the time constants of both the fast and the slow component progressively decrease with increasing doping concentration. Similarities are obtained in with $\mathrm{W}$-doped $\mathrm{TiO}_{2}$ films (as shown in Figure 5B). Figure 5 further reveals that the values of the carrier lifetime in the doped $\mathrm{TiO}_{2}$ films significantly depend on the dopant metals. Comparing the carrier lifetime of $\mathrm{Co} / \mathrm{TiO}_{2}-10 \mathrm{~s}$ in Figure $5 \mathrm{~A}$ with that of $\mathrm{W} / \mathrm{TiO}_{2}$ $10 \mathrm{~s}$ in Figure $5 \mathrm{~B}$, we observe that the value of $\mathrm{Co} / \mathrm{TiO}_{2}-10 \mathrm{~s}$ is almost a factor of two 
faster than that of $\mathrm{W} / \mathrm{TiO}_{2}-10 \mathrm{~s}$. Similarities are also observed in the carrier lifetimes of $\mathrm{Co} / \mathrm{TiO}_{2}-30 \mathrm{~s}$ and $\mathrm{W} / \mathrm{TiO}_{2}-30 \mathrm{~s}$. Similarly, the drift in the trapping carrier time caused by the dopant mass effect is explained by the creation of additional defect states or different distributions of the defect levels in the band gap. ${ }^{39,41}$

Variations in the pump fluence and the concentration effects studied here suggest different behaviors. Whereas the former has no substantial effect on the carrier dynamics, the latter has a pronounced effect on the reduction of the carrier lifetime. Additionally, Co is a promising candidate as a dopant agent since it provides a relatively faster trapping time compared with $\mathrm{W}$, which in turn has a larger mass. More specifically, Figure 6A shows the kinetics of $\mathrm{Co} / \mathrm{TiO}_{2}-10 \mathrm{~s}$ under low $\left(5.3 \mathrm{~mJ} / \mathrm{cm}^{2}\right)$ and high $\left(11.5 \mathrm{~mJ} / \mathrm{cm}^{2}\right)$ pump fluence conditions. As can be seen, the kinetics is relatively comparable in both cases and does not display any significant difference, suggesting that the observed dynamics reflect only carrier trapping and completely exclude any heat contribution to the measured signal. The contribution from lattice heating is considerable, but an increase in the fluence by a factor of two has no significant effect on the kinetics. The photo-generated carrier density is expressed by the following equation: $\mathrm{N}=\mathrm{j}_{\mathrm{p}} \alpha$, where $\mathrm{j}_{\mathrm{p}}$ is the pump fluence (photons $/ \mathrm{cm}^{2}$ ) and $\alpha$ is the absorption coefficient of $\mathrm{TiO}_{2}$ at the associated pump wavelength. The value of $\alpha=0.23 \times 10^{5} \mathrm{~cm}^{-1}$ is determined from the measured absorbance $(\mathrm{OD}=0.184)$ at the pump wavelength and the thickness $(l=80 \mathrm{~nm})$ of $\mathrm{TiO}_{2}$ thin film sample. The spot size of the laser beam is $440 \mu \mathrm{m}$ thus $\mathrm{N}$ is calculated to be $2.13 \times 10^{20} \mathrm{~cm}^{-3}$. Figure $6 \mathrm{~B}$ shows the kinetics of $\mathrm{Co} / \mathrm{TiO}_{2}-30 \mathrm{~s}$ under different excitation conditions at $350 \mathrm{~nm}$ and $475 \mathrm{~nm}$. The lifetime of the trapped states of $\mathrm{Co} / \mathrm{TiO}_{2}-30 \mathrm{~s}$ at $350 \mathrm{~nm}$ excitation (Figure $6 \mathrm{~B}$ ) is slower than the one at $475 \mathrm{~nm}$ excitation. This can be associated with the mechanism whereby a higher excitation energy will inject electrons at an intrinsic energy level above the conduction band edge. Therefore, the electronic wavepacket undergoes intraband transitions in the conduction band, resulting in the fast component as the lifetime becomes slower and decays further to the defect level. In other words, the fast decay is slower at $350 \mathrm{~nm}$ excitation because the decay is convolved together with a growth due to intra-conduction band cooling.

\section{Conclusion}


In summary, the ultrafast carrier dynamics has been examined for the first time for $\mathrm{W} / \mathrm{TiO}_{2}(10 \mathrm{~s}$ and $30 \mathrm{~s})$ and $\mathrm{Co} / \mathrm{TiO}_{2}(10 \mathrm{~s}$ and $30 \mathrm{~s})$ using broadband transient absorption spectroscopy with 120 femtosecond (fs) temporal resolution. The observation of a fast and slow time component was reported for each sample. These time components were attributed to the associated decay of the electronic wavepacket to the defect state near the conduction band and the deep-level trapping state, respectively. The obtained values for the time components are typically on the order of 2-8 ps for the fast one and analogously around 40-160 ps for the slow one, demonstrating the pronounced vital impact of the doping deposition time on the carrier trapping. In addition, our steady-state spectroscopy and imaging and fs transient absorption data demonstrate clearly that Co and $\mathrm{W}$ are present in the $\mathrm{TiO}_{2}$ layer as metal ions rather than oxides. Our results may have implications for applications in electronic devices requiring high-frequency obtained through trapped states, providing fast carrier recombination. We further anticipate that our findings might serve as motivation for further investigation of the ultrafast carrier trapping dynamics in other semiconductor materials.

\section{AUTHOR INFORMATION}

Corresponding Author

* E-mail: omar.abdelsaboor@kaust.edu.sa (O. F. M).

Phone: +966128084491

Notes

The authors declare no competing financial interest.

Acknowledgement

The work reported here was supported by King Abdullah University of Science and Technology.

\section{References}

(1) Asahi, R.; Taga, Y.; Mannstadt, W.; Freeman, A. J. Electronic and Optical Properties of Anatase $\mathrm{TiO}_{2}$. Phys. Rev. B 2000, 61, 7459-7465. 
(2) Etgar, L.; Gao, P.; Xue, Z.; Peng, Q.; Chandiran, A. K.; Liu, B.; Nazeeruddin, M. K.; Grätzel, M. Mesoscopic $\mathrm{CH}_{3} \mathrm{NH}_{3} \mathrm{PbI}_{3} / \mathrm{TiO}_{2}$ Heterojunction Solar Cells. J. Am. Chem. Soc. 2012, 134, 17396-17399.

(3) Lee, S.; Lee, Y.; Kim, D. H.; Moon, J. Carbon-Deposited $\mathrm{TiO}_{2} 3 \mathrm{D}$ Inverse Opal Photocatalysis: Visible-Light Photocatalytic Activity and Enhanced Activity in a Viscous Solution. ACS Appl. Mater. Inter. 2013, 5, 12526-12532.

(4) Paulauskas, I. E.; Modeshia, D. R.; Ali, T. T.; El-Mossalamy, E. H.; Obaid, A. Y.; Basahel, S. N.; Al-Ghamdi, A. A.; Sartain., F. K. Photocatalytic Activity of Doped and Undoped Titanium Dioxide Nanoparticles Synthesised by Flame Spray Pyrolysis. Plat. Met. Rev., 2013, 57, 32-43.

(5) Sun, M.; Zhu, D.; Ji, W.; Jing, P.; Wang, X.; Xiang, W. Exploring the Effect of Band Alignment and Surfaces States on Photoinduced Electron Transfer from $\mathrm{CuInS}_{2} / \mathrm{CdS}$ Core/Shell Quantum Dots to $\mathrm{TiO}_{2}$ Electrodes. ACS Appl. Mater. Inter. 2013, 5, 12681-12688.

(6) Wang, X.; Chen, J. Q.; Barman, A. R.; Dhar, S.; Xu, Q.-H.; Venkatesan, T.; Ariando Static and Ultrafast Dynamics of Defects of $\mathrm{SrTiO}_{3}$ in $\mathrm{LaAlO}_{3} / \mathrm{SrTiO}_{3}$ Heterostructures. Appl.Phys. Lett. 2011, 98, 081916.

(7) Zaleska, A. Doped-TiO2: A Review. Rec. Pat. Eng. 2008, 2, 157-164.

(8) Chen, H.; Nanayakkara, C. E.; Grassian, V. H. Titanium Dioxide Photocatalysis in Atmospheric Chemistry. Chem. Rev. 2012, 112, 5919-5948.

(9) Park, M.-H.; Li, J.-H.; Kumar, A.; Li, G.; Yang, Y. Doping of the Metal Oxide Nanostructure and its Influence in Organic Electronics. Adv. Funct. Mater. 2009, $19,1241-1246$.

(10) Sardar, S.; Sarkar, S.; Myint, M. T. Z.; Al-Harti, S.; Dutta, J.; Pal., S. K. Role of Central Metal Ions in Hematoporphyrin Functionalized Titania in Solar Energy Conversion Dynamics. Phys. Chem. Chem. Phys. 2013, 15, 18562-18570.

(11) Bickley, R. I.; Gonzalez-Carreno, T.; Lee, J. S.; Palmisano, L.; Tilley, R. J. D. A Structural Investigation of Titanium Dioxide Photocatalysts. J. Solid State Chem. 1991, 92, 178-190.

(12) Fujishima, A.; Honda, K. Electrochemical Photolysis of Water at a Semiconductor Electrode. Nature 1972, 238, 37-38.

(13) Graetzel, M. Photoelectrochemical Cells. Nature 2001, 414, 338-344.

(14) Chen, X.; Mao, S. S. Titanium Dioxide Nanomaterials: Synthesis, Properties, Modifications, and Applications. Chem. Rev. 2007, 107, 2891-2959.

(15) Berger, T.; Sterrer, M.; Diwald, O.; Knözinger, E.; Panayotov, D.; Thompson, T. L.; Yates, J. T. J. Light-Induced Charge Separation in Anatase $\mathrm{TiO}_{2}$ Particles. J Phys Chem B 2005, 109, 6061-6068.

(16) Kang, J. U.; Frankel, M. Y.; Huang, J. W.; Kuech, T. F. Ultrafast Carrier Trapping in Oxygen-Doped Metal-Organic Vapor Phase Epitaxy GaAs. Appl. Phys. Lett. 1997, 70, 1560-1562.

(17) Auston, D. H. Impulse-Response of Photoconductors in TransmissionLines. IEEE J. Quantum Electron. 1983, 19, 639-648.

(18) Valdmanis, J. A.; Mourou, G. Subpicosecond Electrooptic SamplingPrinciples and Applications. IEEE J. Quantum Electron. 1986, 22, 69-78. 
(19) Berera, R.; Grondelle, R. v.; Kennis, J. T. M. Ultrafast Transient Absorption Spectroscopy: Principles and Application to Photosynthetic Systems. Photosynth Res. (Springer) 2009, 101, 105-118.

(20) Klimov, V. I. Optical Nonlinearities and Ultrafast Carrier Dynamics in Semiconductor Nanocrystals. J. Phys. Chem. B 2000, 104, 6112-6123.

(21) Villamaina, D.; Bhosale, S. V.; Langford, S. J.; Vauthey, E. Excited-State Dynamics of Porphyrin-Naphthalenediimide-Porphyrin Triads. Phys. Chem. Chem. Phys. 2013, 15, 1177-1187.

(22) Wang, H.; Saxena, C.; Quan, D.; Sancar, A.; Zhong, D. Femtosecond Dynamics of Flavin Cofactor in DNA Photolyase: Radical Reduction, Local Solvation and Charge Recombination. J. Phys. Chem. B 2005, 109, 1329-1333.

(23) Zhang, L.; Kao, Y.-T.; Qi, W.; Wang, L.; Zhong, D. Femtosecond Studies of Tryptophan Fluorescence Dynamics in Proteins: Local Solvation and Electronic Quenching. J. Phys. Chem. B 2006, 110, 18097-18103.

(24) Yamada, Y.; Yasuda, H.; Tayagaki, T.; Kanemitsu, Y. Photocarrier Recombination Dynamics in Highly Excited $\mathrm{SrTiO}_{3}$ Studied by Transient Absorption and Photoluminescence Spectroscopy. Appl. Phys. Lett. 2009, 95, 121112.

(25) Taguchi, S.; Tayagaki, T.; Kanemitsu, Y. Luminescence and Magnetic Properties of Co Doped $\mathrm{ZnO}$ Nanocrystals. IOP Conference Series: Materials Science and Engineering 2009, 6

(26) Maity, P.; Debnath, T.; Akbar, A.; Verma, S.; Ghosh, H. N. Ultrafast Electron-Transfer and -Trapping Dynamics in the Inter-Band-Gap States of $\mathrm{ZrO}_{2}$ Nanoparticles Sensitized by Baicalein. J. Phys. Chem. C 2013, 117, 17531-15539.

(27) Yang, Y.; Zhang, Q.; Zhang, B.; Mib, W. B.; Chen, L.; Lia, L.; Zhao, C.; Diallo, E. M.; Zhang, X. X. The Influence of Metal Interlayers on the Structural and Optical Properties of Nano-Crystalline $\mathrm{TiO}_{2}$ Films. Appl. Surf. Scie. 2012, 258, 45324537.

(28) Sun, J.; Yu, W.; Usman, A.; Isimjan, T. T.; Dgobbo, S.; Alarousu, E.; Takanabe, K.; Mohammed, O. F. Generation of Multiple Excitons in $\mathrm{Ag}_{2} \mathrm{~S}$ Quantum Dots: Single High-Energy versus Multiple-Photon Excitation. J. Phys. Chem. Lett. 2014, $5,659-665$.

(29) El-Ballouli, A. a. O.; Alarousu, E.; Bernardi, M.; Aly, S. M.; Lagrow, A. P.; Bakr, O. M.; Mohammed, O. F. Quantum Confinement-Tunable Ultrafast Charge Transfer at the PbS Quantum Dot and Phenyl-C61-butyric Acid Methyl Ester Interface. J. Am. Chem. Soc. 2014, 136, 6952-6959.

(30) Chambers, S. A.; Thevuthasan, S.; Farrow, R. F. C.; Marks, R. F.; Thiele, J. U.; Folks, L.; Samant, M. G.; Kellock, A. J.; Ruzycki, N.; Ederer, D. L.; Diebold, U. Epitaxial Growth and Properties of Ferromagnetic Co-Doped $\mathrm{TiO}_{2}$ Anatase. Appl. Phys. Lett. 2001, 79, 3467-3469.

(31) Griffin, K. A.; Varela, M.; Pennycook, S. J.; Pakhomov, A. B.; Krishnan, K. M. Atomic-Scale Studies of Cobalt Distribution in $\mathrm{Co}-\mathrm{TiO}_{2}$ Anatase Thin Films: Processing, Microstructure, and the Origin of Ferromagnetism. J. Appl. Phys. 2006, 99, $08 \mathrm{M} 114$.

(32) Lu, L.; Xia, X.; Luo, J. K.; Shao, G. Mn-Doped $\mathrm{TiO}_{2}$ Thin Films with Significantly Improved Optical and Electrical Properties. J. Phys. D: Appl. Phys. 2012, $45,485102$. 
(33) Kment, S.; Kmentova, H.; Kluson, P.; Krysa, J.; Hubicka, Z.; Cirkva, V.; Gregora, I.; Solcova, O.; Jastrabik, L. Notes on the Photo-Induced Characteristics of Transition Metal-Doped and Undoped Titanium Dioxide Thin Films. J. Colloid and Interface Sci. 2010, 348, 198-205.

(34) Gao, Y.; Masuda, Y.; Peng, Z.; Yonezawa, T.; Koumoto, K. Room Temperature Deposition of a $\mathrm{TiO}_{2}$ Thin Film From Aqueous Peroxotitanate Solution. $J$. mater. chem. 2003, 13, 608-613.

(35) Li, G. H.; Yang, L.; Jin, Y. X.; Zhang, L. D. Structural and Optical Properties of $\mathrm{TiO}_{2}$ Thin Film and $\mathrm{TiO}_{2}+2$ wt. $\%$ ZnFe2O4 Composite Film Prepared by r.f. Sputtering. Thin Solid Films 2000, 368, 163-167.

(36) Choudhury, B.; Dey, M.; Choudhury, A. Shallow and Deep Trap Emission and Luminescence Quenching of $\mathrm{TiO}_{2}$ Nanoparticles on Cu Doping. Appl. Nanosci. 2014, 4, 499-506.

(37) Wunderlich, W.; Miao, L.; Tanemura, M.; Jin, P.; Kaneko, K.; Terai, A.; Nabatova-Cabin, N.; Belkada, R. Ab-initio Calculations of the Optical Band Gap of $\mathrm{TiO}_{2}$ Thin Films. Int. J. Nanosci. 2004, 3, 439-445.

(38) Tatlıdil, I.; Bacaksızb, E.; Burukc, C. K.; Breend, C.; Sökmena, M. A Short Literature Survey on Iron and Cobalt Ion Doped $\mathrm{TiO}_{2}$ Thin Films and Photocatalytic Activity of These Films Against Fungi. J. Alloy Comp. 2012, 517, 80-86.

(39) Meier, D. L.; Hwang, J. M.; Campbell, R. B. The Effect of Doping Density and Injection Level on Minority-Carrier Lifetime as Applied to Bifacial Dendritic Web Silicon Sorlar-Cells. IEEE Trans. Electron Dev. 1988, 35, 70-79.

(40) Yamada, Y.; Kanemitsu, Y. Blue Photoluminescence of Highly Photoexcited Rutile $\mathrm{TiO}_{2}$ : Nearly Degenerate Conduction-band Effects. Phys. Rev. B 2010, 82, 113103 .

(41) Dhaka, V. D. S.; Tkachenko, N. V.; Lemmetyinen, H.; Pavelescu, E. M.; Guina, M.; Tukiainen, A.; Konttinen, J.; Pessa, M.; Arstila, K.; Keinonen, J.; Nordlund, K. Effects of Heavy-Ion and Light-Ion Irradiation on the Room Temperature Carrier Dynamics of InGaAs/GaAs Quantum Wells. Semicond. Sci. Technol. 2006, 21, 661-664. 
Table caption

Table 1: $\mathrm{Co} /(\mathrm{Co}+\mathrm{Ti})$ elementary ratios in $\mathrm{Co} / \mathrm{TiO}_{2}-10 \mathrm{~s}$ and $\mathrm{Co} / \mathrm{TiO}_{2}-30$ s thin films.

\begin{tabular}{|l|l|l|l|}
\hline \multirow{2}{*}{ sample } & \multicolumn{3}{|c|}{$\mathrm{Co} /(\mathrm{Co}+\mathrm{Ti})$ ratio } \\
\cline { 2 - 4 } & $\mathrm{P} 1$ & $\mathrm{P} 2$ & $\mathrm{P} 3$ \\
\hline $\mathrm{Co} / \mathrm{TiO}_{2}-10 \mathrm{~s}$ & $26.923 \%$ & $5.000 \%$ & $2.299 \%$ \\
\hline $\mathrm{Co} / \mathrm{TiO}_{2}-30 \mathrm{~s}$ & $66.019 \%$ & $6.154 \%$ & $2.899 \%$ \\
\hline
\end{tabular}

\section{Figure captions}

Figure 1: A high-resolution TEM image of a $\mathrm{Co} / \mathrm{TiO}_{2}-30$ s film (A). A STEM image of a $\mathrm{Co} / \mathrm{TiO}_{2}-30$ s film (B). P1 refers to the position in the metal layer, $\mathrm{P} 2$ and $\mathrm{P} 3$ refer to the positions at the edge and the center of $\mathrm{TiO}_{2}$ layer, respectively. EELS spectra were taken at positions $\mathrm{P} 1, \mathrm{P} 2$, and $\mathrm{P} 3$ for analyzing the distribution of $\mathrm{Co}$ in the multilayer thin films.

Figure 2: The steady-state absorption spectra of a $\mathrm{TiO}_{2}$ film (A), $\mathrm{Co} / \mathrm{TiO}_{2}-10 \mathrm{~s}$ and $\mathrm{Co} / \mathrm{TiO}_{2}-30$ s films (B) and $\mathrm{W} / \mathrm{TiO}_{2}-10 \mathrm{~s}$ and $\mathrm{W} / \mathrm{TiO}_{2}-30$ s films (C). $\mathrm{TiO}_{2}-\mathrm{M}-\mathrm{TiO}_{2}$ multilayer thin films are red-shifted compared with the non-doped $\mathrm{TiO}_{2}$ films, indicating that the band structure of the semiconductor oxide is modified significantly by metal doping.

Figure 3: The experimental setup of femtosecond transient absorption spectroscopy showing the integration of the ultrafast Helios UV-NIR spectrometers (Ultrafast systems, FL, USA) with both a Spitfire Pro 35F-XP regenerative amplifier (Spectra physics) and a TOPAS-C two-stage parametric amplifier. 
Figure 4: Average transient absorption spectra of a $\mathrm{TiO}_{2}$ film (A), $\mathrm{W} / \mathrm{TiO}_{2}-30$ s film (B) and $\mathrm{Co} / \mathrm{TiO}_{2}-30$ s film $(\mathrm{C})$ at different time delays and an excitation of $350 \mathrm{~nm}$.

Figure 5: Comparison of the different doping concentration effects on the kinetics: (A) $\mathrm{TiO}_{2}, \mathrm{Co} / \mathrm{TiO}_{2}-10 \mathrm{~s}$ and $\mathrm{Co} / \mathrm{TiO}_{2}-30$ s films. (B) $\mathrm{W} / \mathrm{TiO}_{2}-10 \mathrm{~s}$ and $\mathrm{W} / \mathrm{TiO}_{2}-30$ s films. A global fitting procedure for the carrier trapping indicates that a significant effect of the doping concentration.

Figure 6: (A) The kinetics of a $\mathrm{Co} / \mathrm{TiO}_{2}-10 \mathrm{~s}$ film under different pump fluences, clearly indicating that the observed dynamics reflect only carrier trapping and completely exclude any contribution of heat to the measured signal. (B) The kinetics of a $\mathrm{Co} / \mathrm{TiO}_{2}-$ 30s film under different excitation conditions. 

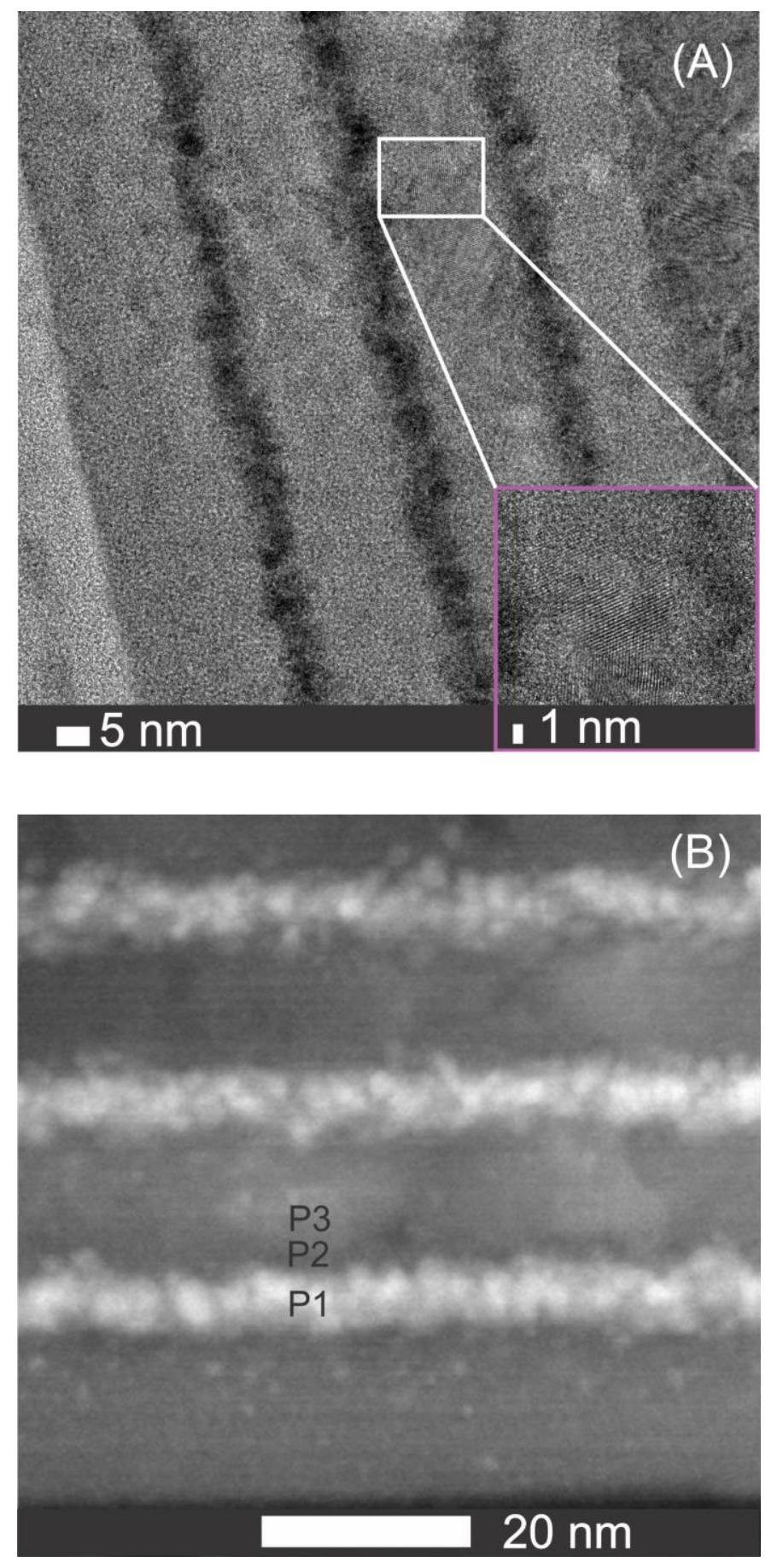

Figure 1: 


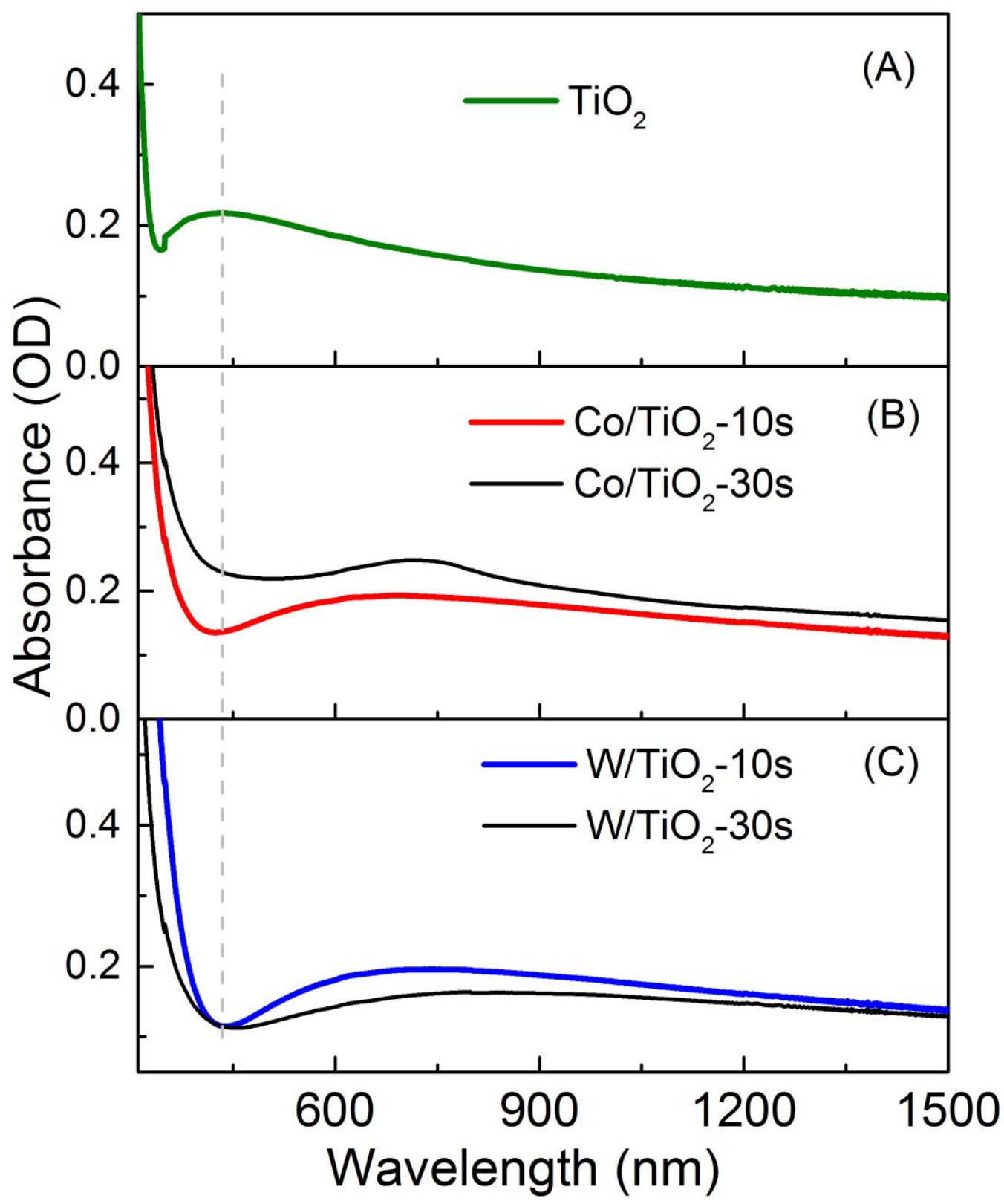

Figure 2: 


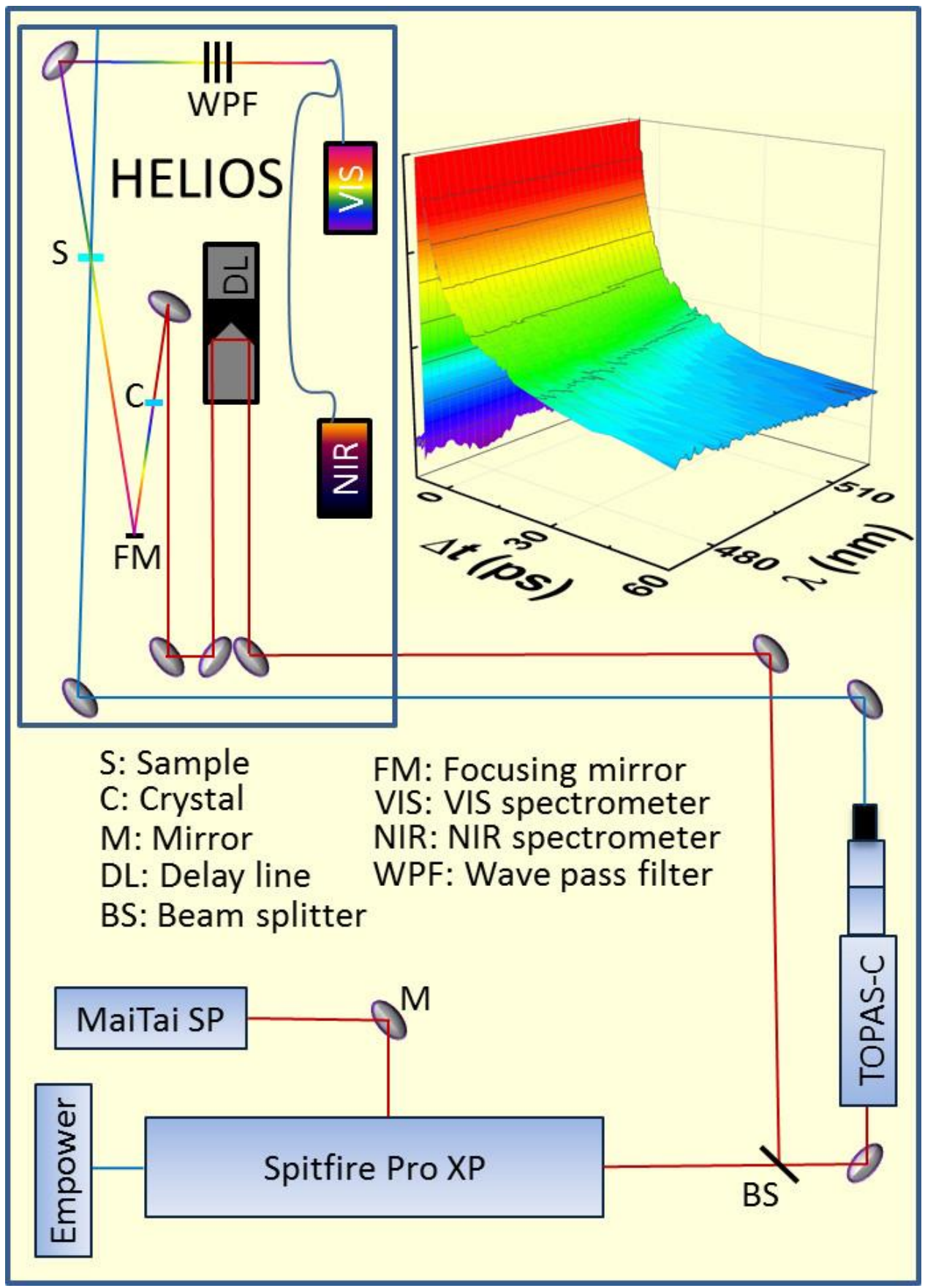

Figure 3: 


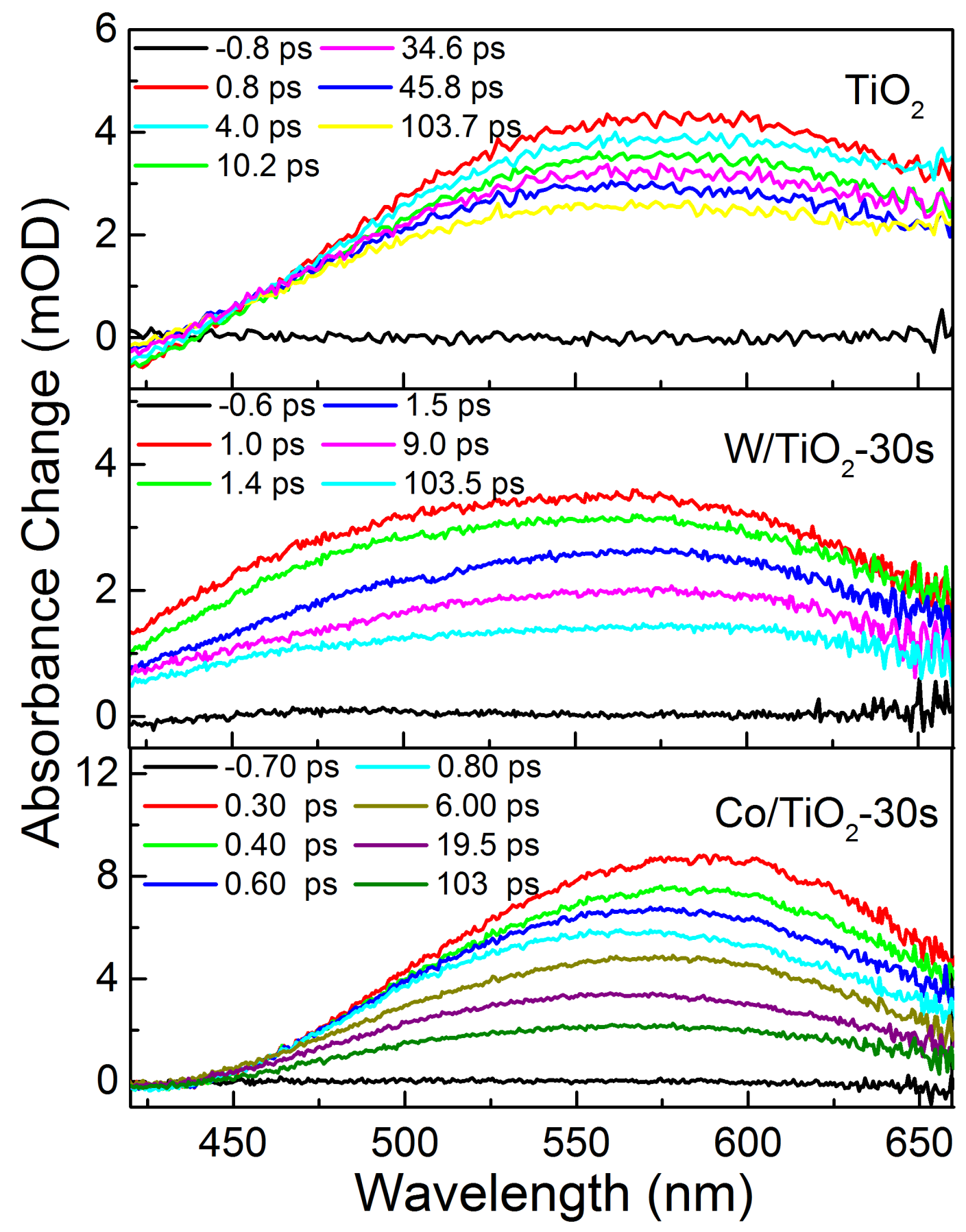

Figure 4: 


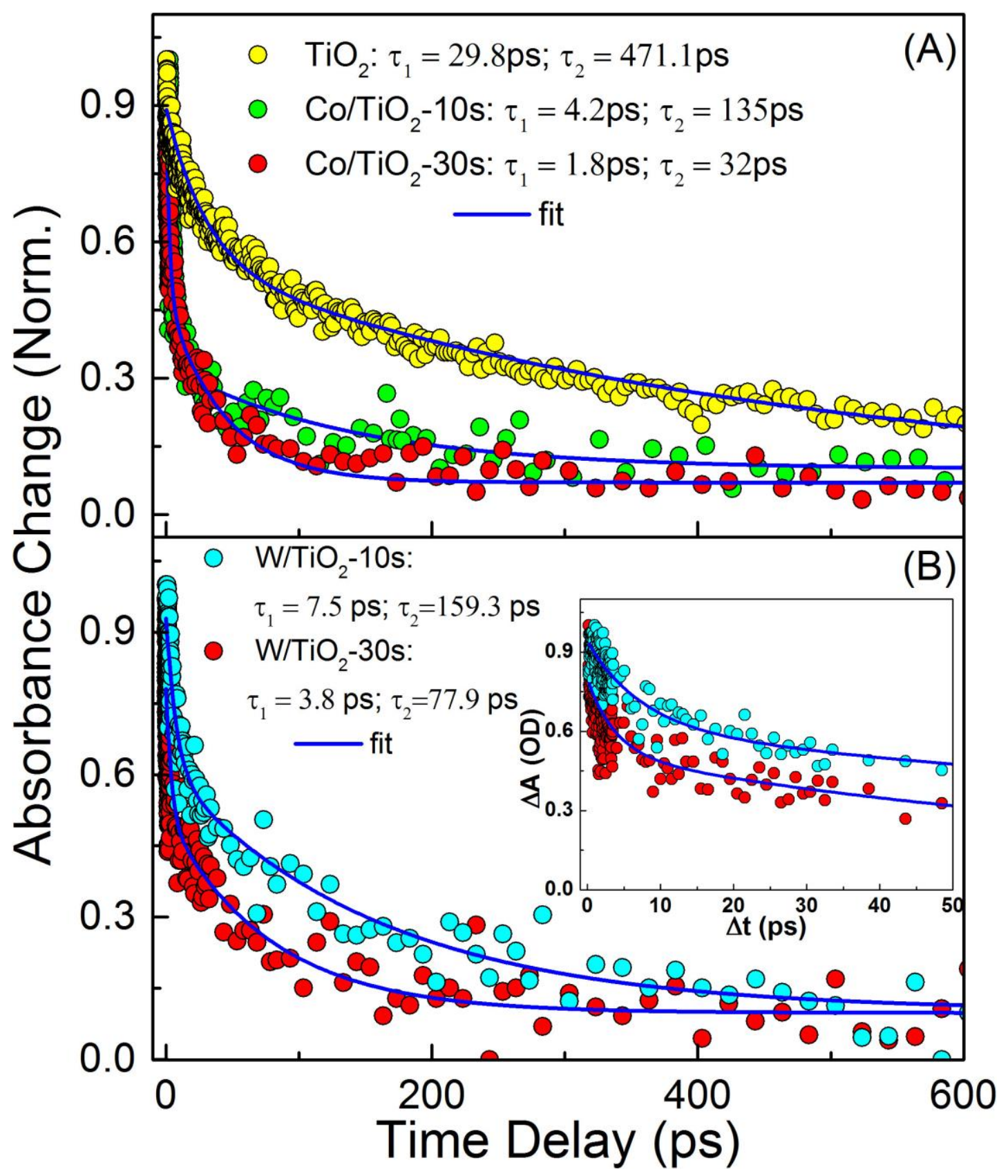

Figure 5: 


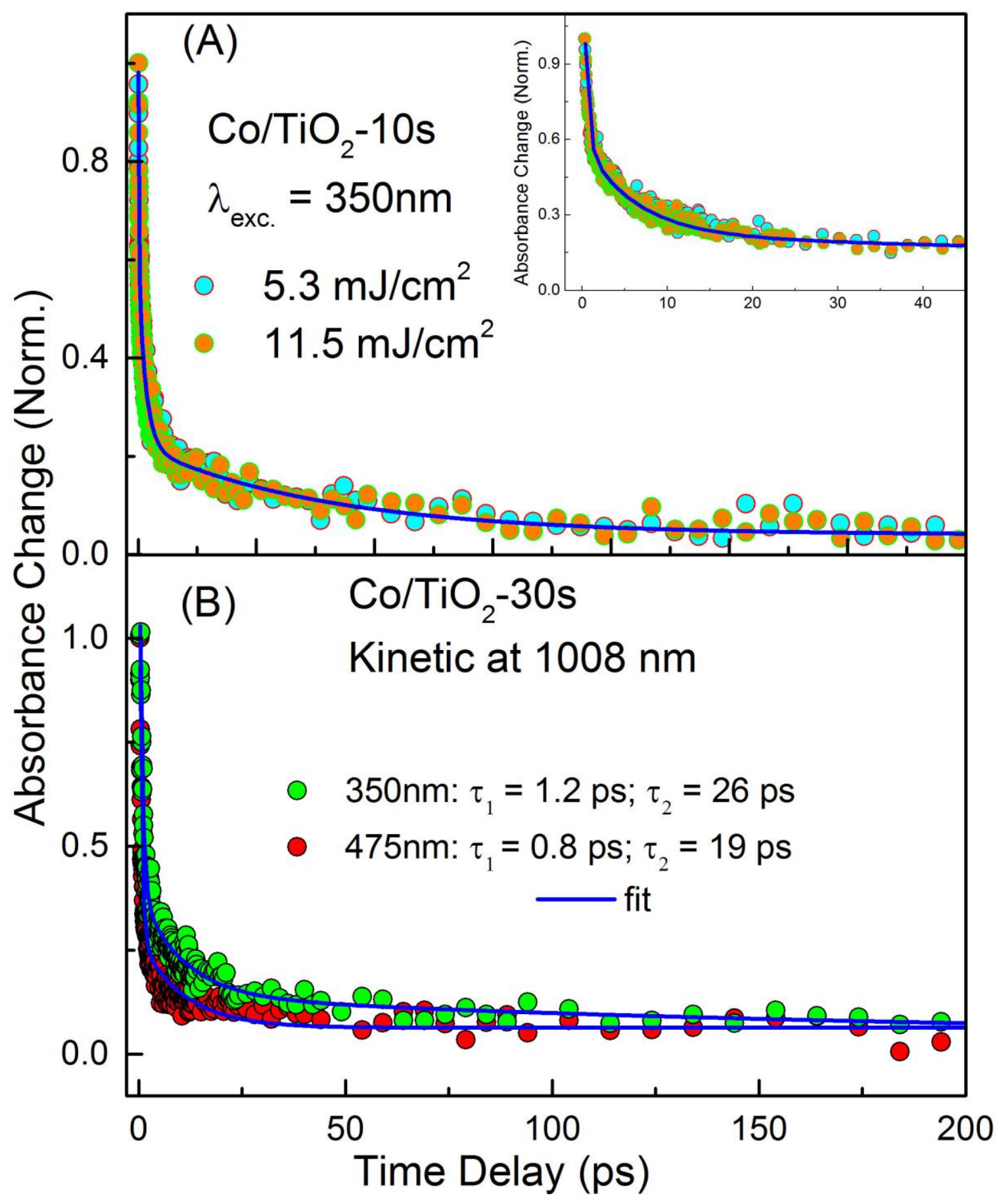

Figure 6: 


\section{TOC Graphic}

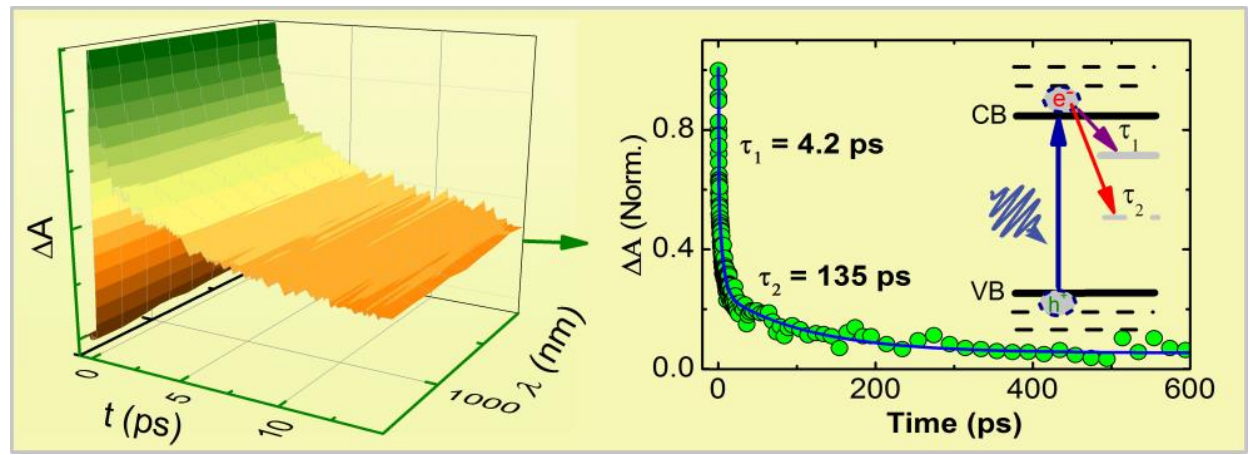

Femtosecond transient absorption results demonstrate that there are two time components for carrier trapping in metal-doped titanium dioxide $\left(\mathrm{TiO}_{2}\right)$ thin films: a fast one that is directly associated with carrier trapping to the defect state in the vicinity of the conduction band and a slow one that is attributed to the carrier trapping at the deep-level state from the conduction band. 